\title{
The influence of feeding enrichment on the behavior of small felids (Carnivora: Felidae) in captivity
}

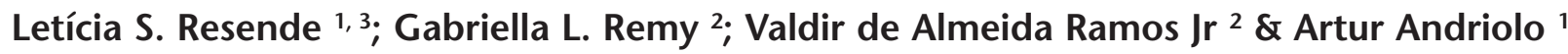 \\ ${ }^{1}$ Mestrado em Biologia e Comportamento Animal , Instituto de Ciências Biológicas, Universidade Federal de Juiz de Fora. \\ Campus Universitário, Martelos, 36036-900 Juiz de Fora, Minas Gerais, Brasil. \\ 2 Fundação Riozoo. Parque Quinta da Boa Vista, São Cristóvão, 20940-040 Rio de Janeiro, Rio de Janeiro, Brasil. \\ ${ }^{3}$ Corresponding author. E-mail: leticiasresende@gmail.com
}

\begin{abstract}
Animals in captivity are frequently exposed to environmental deprivation resulting in abnormal behaviors that indicate distress. The aim of the present study was to evaluate the effect of the "surprise pack" environmental enrichment technique in improving the welfare of small neotropical felids in captivity. In order to accomplish this, we used five individuals from the Rio de Janeiro Zoo. The experiment was divided into three steps corresponding to: I) period prior to the enrichment, II) period in which the animals were being submitted to enrichment stimuli, and III) period after the enrichment. In phase II, we observed a significant reduction in abnormal behavior compared to phases I and III. Only in phase II did the animals demonstrate the following behaviors: predation, social interaction and territory demarcation. However, in this same phase, the mean time spent interacting with the enrichment throughout the day showed a decrease.
\end{abstract}

KEY WORDS. Neotropical felids; surprise pack; zoological.

Felidae encompasses 37 species, of which 10 are found in South America (Nowell \& JACKSON 1996). All neotropical felids are endangered, either due to degradation and fragmentation of their habitats or to predatory hunting (OliverRa 1994).

The maintenance of captive populations has an essential function in environmental education and research programs (LAw et al. 1997, Hosey 1997) and constitutes an important genetic legacy (Dobson \& SMith 2000). However, inappropriate environments adversely affect animal behavior, mainly due to the lack of stimuli (BoERE 2001). In captivity, animals may not have the motivation, opportunity or need to exhibit a series of behaviors considered normal for the species (MACPheE 2002).

Under these conditions, many individuals develop abnormal behaviors that differ in form, frequency or context from the behaviors displayed by conspecifics living in the wild (BROOM \& JoHnson 1993). Such behaviors include coprophagy, inactivity, hyperaggressivity, hypersexuality, low socialization, selfmutilation, and stereotyped behaviors, among others (BoERE 2001).

Welfare can be provided through different techniques of environmental enrichment. Environmental enrichment considerably minimizes the boredom and depression that result from captivity by creating an interactive and complex environment that helps captive animals to behave in a more natural manner (SHEPHERDSON et al. 1993).

Feeding enrichment, one of the most common forms of environmental enrichment, leads to an increase in time spent feeding by inducing foraging behaviors (Young 2003).
Environmental enrichment plans are difficult to develop (Mellen et al. 1998) for captive carnivores, due to their feeding habits and spatial needs. LINDBURG (1988) describes the feeding behavior of felids in four steps: first, the prey is located through vision, smell and/or hearing; next the predator moves furtively and approaches the prey (stalking); when it is near the prey, the predator chases it (hunting); and finally, the carnivore kills the prey. The prey is generally killed with a bite to the nape of the neck or through asphyxia.

Negative reactions from the public and ethical issues prevent zoos from feeding live animals to carnivores. Moreover, concerns about providing a balanced diet to captive animals have resulted in a diet consisting of processed meat that remotely resembles the natural prey (MelLen et al. 1998).

Thus, studies that systematically aim to create and/or verify potential methods of environmental enrichment aimed to felids are necessary in order provide us with a better means to handle these animals and ensure their physical and mental balance. The aim of this research was to evaluate an environmental feeding enrichment technique for three species of neotropical felids in captivity, Leopardus geoffroyi (d'Orbigny and Gervais, 1844), Leopardus tigrinus (Schreber, 1775), Leopardus wiedii (Schinz, 1821), and to determine behavioral changes and possible improvements to their welfare. These species were chosen for our study because they present low birth rate in captivity, that may be related to high susceptibility to stress resulting from inappropriate husbandry and management (CARlstead et al.1992). 


\section{MATERIAL AND METHODS}

The study area was the Reproduction Center for Small Felids, Rio de Janeiro Zoo - RIOZOO Foundation - located at Quinta da Boa Vista Park, in the neighborhood of São Cristóvão. The Center has a total area of $273 \mathrm{~m}^{2}$, and is divided into nine enclosures. Enclosures $\left(15 \mathrm{~m}^{2}\right)$ are made of stone masonry walls, with the exception of the front part, which is made of wire mesh. The floor of the enclosures is covered with dust and concrete substrate. Plants and trunks are spread randomly, and a wooden box measuring $40 \mathrm{~cm}^{3}$ is located in the upper part, which is used as a shelter. The animals remain in a restricted area, and have contact only with their keepers and technicians.

Five individuals of three different species were studied: two individuals of Geoffroy's cat, L. geoffroyi, one individual of oncilla, L. tigrinus, and two individuals of margay, L. wiedii (Tab. I). All animals had been born in free-living environments and have been in captivity between 2-10 years. During this study, including the days of enrichment, the animals continued to be fed regularly between 2:00 p.m. and 3:00 p.m. on commercial cat food, morsels of chicken and lab rats.

The surprise pack was used as environmental feeding enrichment. This pack consisted of a brown paper bag measuring $60 \mathrm{~cm}^{2}$, without any metal or plastic structure or adhesive tape, filled with around 10 morsels of raw beef hidden in the middle of dry alfalfa, and weighing approximately 15 grams each. The packs were not sealed, bud the edges were crumpled. One pack, randomly placed in each enclosure, always in a different place, was given to each individual. This environmental enrichment technique was based on articles published in the journal Shape of Enrichment (Bush 1998, KNAPIK 1995, Neufeld 1999, PHILLIP 1999), and had been previously tested in our enrichment program at RIOZOO.

Behavioral data were collected in May and June, 2005. An "ABA" design was employed consisting of baseline observations (Phase I), enrichment observations (Phase II), and post enrichment baseline observation (Phase III) totaling 35 hours of observations.

Baseline observations (Phase I) were carried out for nine consecutive days with the aim of establishing the behavioral categories presented by the animals studied. Each enclosure was observed for 10 minutes in the morning and for 10 minutes in the afternoon. A qualitative and quantitative ethogram was then constructed.

During the treatment (Phase II), enrichment items were given to the felids daily for seven days, always in the morning. The enrichment was placed randomly on the floor of the enclosure. After the enrichment was placed, the enclosure was observed for 30 minutes, until the next enrichment was placed in the next enclosure. In the afternoon each enclosure was observed for 10 minutes.

Post enrichment baseline observations (Phase III) were made for seven consecutive days, 30 days after treatment. This step aimed to ascertain how long the results of phase II would last. Each enclosure was observed for 10 minutes in the morning and for 10 minutes in the afternoon. The frequency of abnormal behavior was used as a welfare indicator. The behavior of animals during the study was recorded using the Focal Animal Method (AltMann 1974). The observation sequence of each enclosure underwent some changes in order to avoid data dependency on different days.

In order to compare between the behavioral patterns in the different phases we used the Friedman nonparametric analysis of variance. Each individual was used as its own control. The Wilcoxon test was used to compare the mean duration of abnormal behavior between two phases. To analyze the duration of each individual's interaction with the enrichment during Phase II, we applied a linear regression analysis.

\section{RESULTS}

In phase I, 12 behavioral categories were identified (moving, grooming, drinking, eating, pacing, resting, inside the box, exploring, not visible, growling, urinating, and vigilant). These categories were classified as active, inactive or abnormal for further comparisons. The categories analyzed presented different duration (Friedman: $\chi^{2}=41.62, p<0.001$ ), with the "resting" behavior presenting the largest mean duration, followed by the "inside the box" behavior, and the "pacing" behavior (Tab. II).

No significant difference was observed in the average frequency of activity between the three observation phases (Phase $\mathrm{I}=0.10 \mathrm{seg} / \mathrm{min} \pm 0.02$, Phase $\mathrm{II}=0.18 \mathrm{seg} / \mathrm{min} \pm 0.02$, Phase III $=0.08 \pm 0.02)\left(\right.$ Friedman: $\chi^{2}=2.8, \mathrm{p}=0.240$ ).

The animals presented a mean reduction of time spent interacting with the the enrichment pack throughout the days in Phase II (Friedman: $\chi^{2}=17.37, \mathrm{p}=0.008$ ) (Fig. 1).

Table I. Arrangement of individuals observed during the study at the Reproduction Center for Small Felids- RIOZOO Foundation.

\begin{tabular}{lcccc}
\hline \multicolumn{1}{c}{ Animal } & Enclosure & Age & Gender & Endangered \\
\hline Leopardus geoffroyi (1) & 1 & 15 years old & Male & near threatened \\
Leopardus geoffroyi (2) & 2 & 8 years old & Male & near threatened \\
Leopardus wiedii (1) & 3 & - & Female & near threatened \\
Leopardus wiedii (2) & 3 & Female & near threatened \\
Leopardus tigrinus & 4 & Male & vulnerable \\
\hline
\end{tabular}




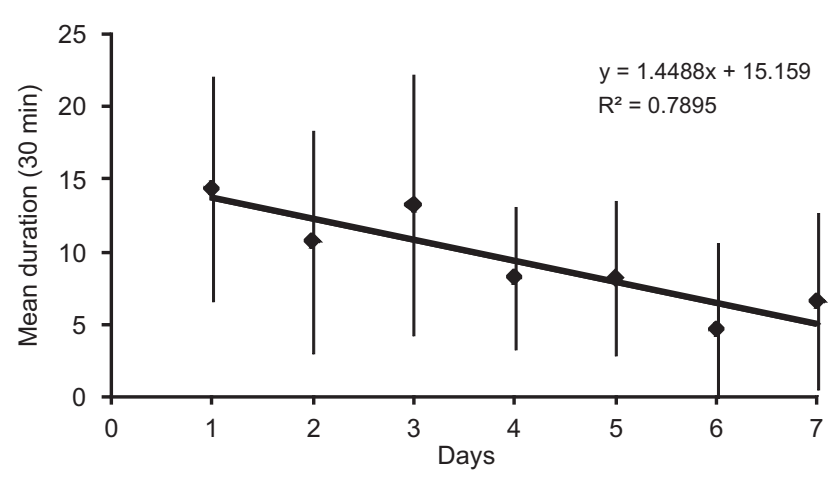

Figure 1. Duration of interaction with the enrichment throughout the days in Phase II for all the animals. The straight line was obtained with the data distribution model represented by equation $(y=-1.4488 x+15.159)$ where $R^{2}=0.789$.

There was a significant reduction in the abnormal behavior of the animals when they were submitted to the enrichment stimulus (Phase II). The frequency of pacing displayed by Leopardus tigrinus varied significantly across the three phases
(Phase I, Phase II and Phase III) (Friedman: $\chi^{2}=8.66, \mathrm{p}=0.010$ ). Pacing was significantly higher before enrichment (Phase I) $(1,09 \mathrm{seg} / \mathrm{min} \pm 0,31)$ than during the enrichment (Phase II) $(0.23 \mathrm{seg} / \mathrm{min} \pm 0.19)$ (Wilcoxon: $\mathrm{Z}=2.5, \mathrm{p}=0.010)$. Significant differences were also observed in the frequency of pacing during enrichment compared to the average frequency of that behavior in the period after the enrichment $(0.48 \mathrm{seg} / \mathrm{min} \pm$ 0.23) (Wilcoxon: $\mathrm{Z}=1.96, \mathrm{p}=0.040$ ) (Fig. 2).

Leopardus geoffroyi (1) presented a significant difference in abnormal behavior frequency across the three observation phases (Friedman: $\chi^{2}=35.15, \mathrm{p}<0.001$ ). Pacing was significantly higher before $(0.33 \mathrm{seg} / \mathrm{min} \pm 0.08)$ than during the enrichment (0.03 seg/min \pm 0.01$)$ (Wilcoxon: $\mathrm{Z}=4.14, \mathrm{p}<$ 0.001). Similarly, when comparing the frequency of pacing during (Phase II) and after enrichment (Phase III) a significant difference was observed, being higher in the Phase III $(0,36$ seg/min $\pm 0,06)$ then during the enrichment (Phase III) (Wilcoxon: $\mathrm{Z}=5.34, \mathrm{p}<0.001$ ) (Fig. 3).

Similarly, for Leopardus wiedii (1) a significant difference was observed in the abnormal behavior frequency across the three phases (Friedman: $\chi^{2}=20.69, \mathrm{p}<0.001$ ). Also significant difference was observed between the frequency of pacing be-
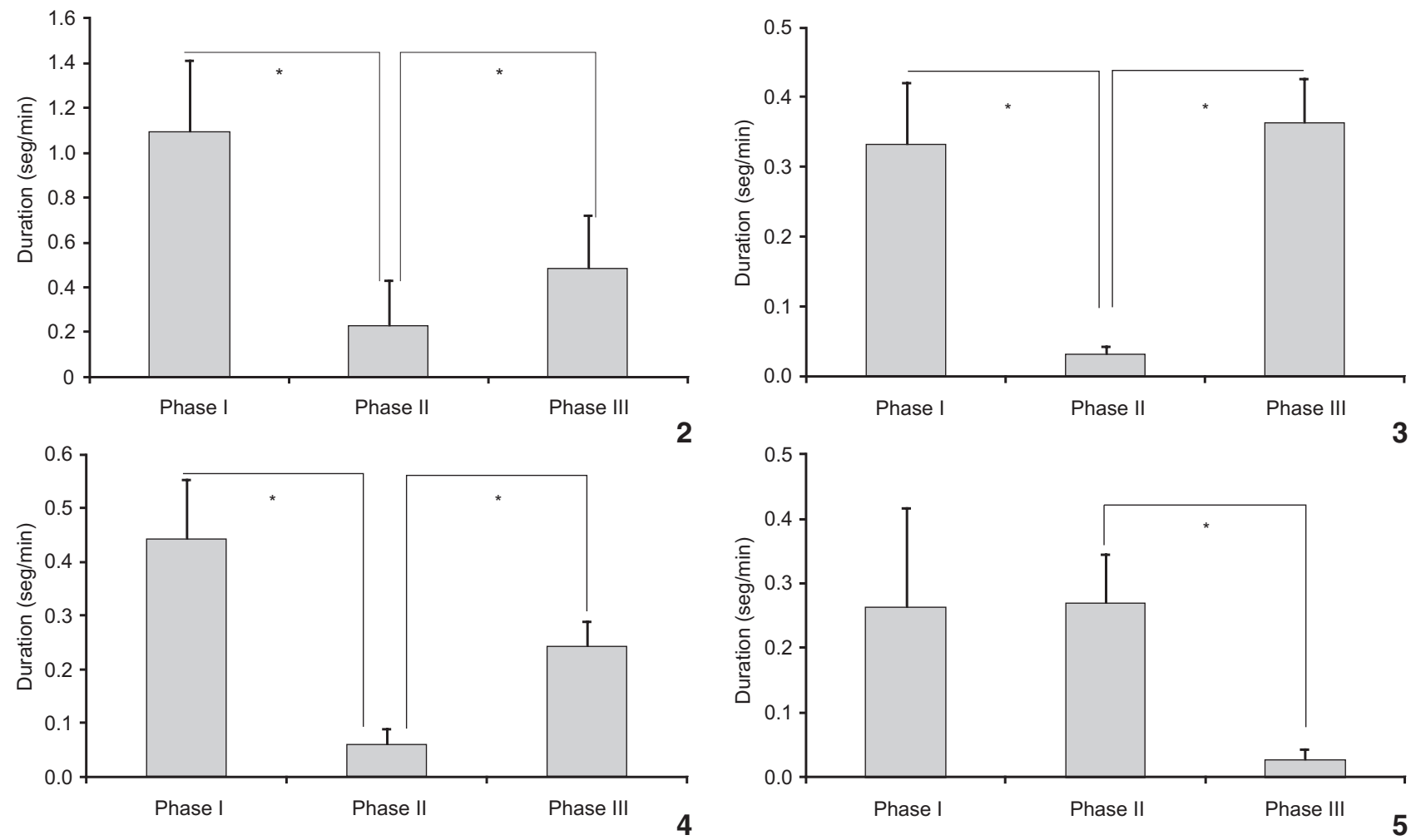

Figures 2-4. Mean duration (seg/min) of abnormal behavior in the three phases registered in the Reproduction Center for Small Felids, RIOZOO Foundation for: (2) L. tigrinus; (3) L.geoffroyi; (4) L. wiedii; (5) L. geoffroyi. The Phase I refer to baseline observations, the Phase II refer to enrichment observations and the Phase III refer to post enrichment baseline observation. 
Table II. Mean duration of behaviors displayed by small neotropical felids kept in the Center for Small Felids- RIOZOO Foundation. Total observation time. (180 minutes).

\begin{tabular}{|c|c|c|c|}
\hline Behavior & Definition & Behavioral category & Mean duration $( \pm \mathrm{SE})$ \\
\hline Moving & Movement towards a specific direction with an aim & active & $9,43 \pm 1,54$ \\
\hline Grooming & Animal cleaning and licking itself & active & $4,70 \pm 1,26$ \\
\hline Drinking & Animal drinking water & active & $0,07 \pm 0,05$ \\
\hline Eating & Grinding an object, usually with its canines & active & $6,47 \pm 2,09$ \\
\hline Pacing & Repetitive walking, without apparent aim "Pacing" & abnormal & $27,55 \pm 6,96$ \\
\hline Resting & Animal in resting position (lying or sitting), eyes open or closed & inactive & $77,33 \pm 21,04$ \\
\hline Inside the box & Animal inside a wooden box & inactive & $49,26 \pm 17,60$ \\
\hline Exploring & Animal moving attentively, normally sniffing the ground and the walls & active & $2,48 \pm 0,77$ \\
\hline Not visible & Animal stays in an area which is visually inaccessible to observer & & $0.75 \pm 0,31$ \\
\hline Growling & Animal vocalizing & active & $0,08 \pm 0,05$ \\
\hline Urinating & Animal urinating, this can be related to territory demarcation & active & $0,08 \pm 0,04$ \\
\hline Vigilant & Alert, attentive standing or sitting & active & $3,20 \pm 1,20$ \\
\hline
\end{tabular}

fore enrichment $(0.44 \mathrm{seg} / \mathrm{min} \pm 0.11)$ and during enrichment (0.06 seg/min \pm 0.03 ) (Wilcoxon: $\mathrm{Z}=3.62$, $\mathrm{p}<0.001)$. Significant differences were also observed in the frequency of pacing during enrichment compared to the average frequency of that behavior in the period after the enrichment $(0.24 \mathrm{seg} / \mathrm{min} \pm$ 0.04) (Wilcoxon: $\mathrm{Z}=3.55, \mathrm{p}<0.001$ ) (Fig. 4).

For Leopardus geoffroyi (2) a significant difference in the frequency of stereotypic pacing across the phases was observed (Friedman: $\left.\chi^{2}=19.44, \mathrm{p}<0.001\right)$. However the frequency of pacing before enrichment $(0.26 \mathrm{seg} / \mathrm{min} \pm 0.15)$ did not differ from the frequency of this behavior during enrichment $(0.26 \pm$ 0.07) (Wilcoxon: $Z=1.7 ; p=0.080$ ) (Fig. 5).

Leopardus wiedii (2) did not present abnormal behavior, and was therefore excluded from these results.

During this study, it was observed that the animals presented behavioral patterns related to the capture of prey only when they were submitted to the enrichment stimulus. Such behaviors include: approaching the prey slyly, in this case, the enrichment; territory demarcation; and social interaction. During the enrichment, the animals carried the morsels of meat to the tree trunks or to a wooden box located at the top of the enclosure. Such behavior was not registered when these animals were fed regularly.

\section{DISCUSSION}

The behavioral pattern analysis in the phase before the enrichment stimulus showed that the animals spend most of their time inactive. The data agree with the study of MelLen et al. (1998) which observed that small felids remain inactive $57 \%$ of the time during daylight hours. Studies that report the diurnal and nocturnal activity patterns for free-living small felids are rare. According to Johnson \& Franklin (1991), Leopardus geoffroyi can remain inactive for $75 \%$ of the time during daytime.

Thus, efforts to increase activities of captive felids during the day as part of the environmental enrichment can be useless and unnatural, since many species have crepuscular and nocturnal habits (Hutchins et al. 1984). According to Mellen et al. (1998), the enrichment should change the way these animals use their activity time, decreasing the hours spent on pacing and stimulating natural behaviors.

The surprise pack provision had a positive effect on the behavior of the subjects. This conclusion comes from the observation that the animals spent significantly less time on abnormal behaviors when they were submitted to the enrichment stimulus. The data agree with the study of MEREDith et al. (2003) which evaluated the effect of two feeding enrichment techniques on five individuals belonging to two species of felids: African lions and tigers. Presenting live fish increased the variety and frequency of feeding behaviors, while presenting the horse leg bone only increased frequency. McPheE (2002), using carcasses as environmental feeding enrichment, observed an increase in natural behaviors and a reduction in stereotyped ones.

Collectively, these studies suggest that a greater enclosure complexity associated with new stimuli, such as different ways of presenting food, contribute to a reduction in abnormal behavior in captive animals, potentially increasing their physical and psychological well-being.

In addition, feeding environmental enrichment programs for small felids in captivity can stimulate the performance of behaviors presented by their wild conspecifics. The performance of natural behaviors in captivity in response to environmental enrichment can be extremely valuable in reintroduction pro- 
grams (SHEPHERDSON et al. 1998). It is essential that captive animals are provided with environments that are rich enough to allow the performance and maintenance of typical behaviors for the species, needed for their survival in a natural environment (SHEPHERson et al. 1998). The two primary behavioral patterns that allow immediate survival are predation and the ability to look for food (Young 2003).

In general, the duration of the interaction with the enrichment object varied significantly throughout the days. We observed that the interest displayed by the individuals decreased during the enrichment phase. According to Mellen et al. (1998), small felids, like other organisms, get used to new environmental conditions or stimuli relatively fast. Due to this fact, environmental enrichment plans must be dynamic and constantly changing to effectively stimulate the performance of more characteristic behaviors in captivity.

Additionally, according to Mellen et al. (1998), no enrichment type causes an indefinite change - in behavior. This fact was observed in this study, since in the post enrichment phase, which lasted approximately 30 days after the stimulus had ended, the animals displayed abnormal behavior most of the time.

Studies related to environmental enrichment techniques have increased around the world in the last years. In Brazil, these techniques are still little explored, hence the importance of this study to provide deserving conditions for the well-being of captive animals.

\section{ACKNOWLEDGMENTS}

We thank the Zoológico do Rio de Janeiro (Fundação RIOZOO) for their collaboration. Leticia de Souza Resende received a scholarship from CAPES.

\section{LITERATURE CITED}

Altmann, J. 1974. Observational study of behavior: sampling methods. Behaviour 49: 227-267.

Boere, V. 2001. Environmental enrichment for Neotropical primates in captivity: a review. Ciência Rural 31: 451-460.

Broom, D. M. \& K.G. Johnson. 1993. Estresse and animal welfare. London, Chapman \& Hall, Animal Behaviour Series, 211p.

Bush, M. 1998. Tepee Feeders for Small Cats. The Shape of Enrichment 7 (1): 6.

Carlstead, K.; J.L.Brown; S.L. Monfort.; R. Killens \& D.E. Wildt. 1992. Urinary monitoring of adrenal responses to psychological stressors in domestic and nondomestic felids. Zoo Biology 11:165-76.
Dobson, H. \& R.F. Smith. 2000. What is stress, and how does it affect reproduction? Animal Reproduction Science 60 (61): 743-753.

Hosey, G.R. 1997. Behavioral research in zoos: academic perspectives. Applied Animal Behaviour Science 51: 199-207.

Hutchins, M.; D. Hancocks \& C. Crockett. 1984. Naturalistic solutions to the behavioural problems of captive animals. Zoologishe Garten 54: 28-42.

Johnson, W.E. \& W.L. FrankLin. 1991. Feeding and spatial ecology of Felis geoffroyi in southern Patagonia. Mammalia 72: 815820.

KNAPIK, D. 1995. Environmental Enrichment for Felines. The Shape of Enrichment 4 (1): 9.

LaW, G.; A. MacDonald \& A. Reid. 1997. Dispelling some common misconceptions about the keeping of felids in captivity. International Zoo Yearbook 35: 197-207.

LINDBURG, D.G. 1988. Improving the feeding of captive felines through application of field data. Zoo Biology 7: 211-218.

McPhee, M.E. 2002. Intact Carcasses as Enrichment for Large Felids: Effects on On - and Off Exhibit Behaviors. Zoo Biology 21: 37-47.

Mellen, J.D.; M. Hayes \& D. Sheperdson. 1998. Captive environments for small felids, p. 184-201. In: D. SHePERDSON; J.D. MELlen \& M. Hutchins (Eds). Second Nature. Environmental enrichment for captive animals. Washington, D.C, Smithsonian Institution, II+376p.

Meredith J. B.; M.A. Bloomsmith \& T.L. Maple. 2003. To hunt or not hunt? A feeding enrichment experiment with captive large felids. Zoo Biology 22: 189-198.

Neufeld, D. 1999. Creating Artificial Prey for Carnivores. The Shape of Enrichment 8 (4): 11-13.

Nowell, K. \& P. JACKSON. 1996. Wild cats, status survey and conservation action plan. Gland, IUCN/SSC, Cat Specialist Group, World Conservation Union, II+382p.

OliveIRA, G.T. 1994. Neotropical cats: ecology and conservation. São Luís, Editora Universidade Federal do Maranhão, I+244p.

Phillip, R. 1999. Enrichment Bucket. The Shape of Enrichment 8 (1): 6.

Shepherdson, O.J.; K. Carlstead; J.D. Mellen \& J. Seidenslicker. 1993. Influence of Food Presentation on the Behaviour of Small Cats in Confined Environments. Zoo Biology 12: 203-216.

Sheperdson, D.; J.D. Mellen \& M. Hutchins. 1998. Second Nature. Environmental Enrichment for Captive Animals. Washington, D.C. Smithsonian Institution, I+350p.

YounG, J.R. 2003. Environmental enrichment for captive animals. Oxford, Blackwell Science, I+228p.

Submitted: 11.III.2009; Accepted: 14.XII.2009.

Editorial responsibility: Kleber del Claro 